\title{
A RECEPÇÃO DE VIEIRA POR GARRETT, CAMILO E TEÓFILO
}

\author{
Paulo Motta Oliveira \\ Universidade Federal de Minas Gerais
}

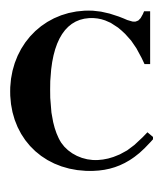

omemorando o bicentenário da morte de Vieira, foi publicado, há um século, o livro Trechos Selectos do Padre António Vieira. Na "Notícia Biográfica" presente neste volume, o autor deste texto, José Fernando de Sousa, afirma:

Ao Século do regalismo pombiano e da filosofia errônea e superficial da Enciclopédia sucedeu o século atual, que entre os seus títulos de benemerência conta a renovação dos estudos históricos. Soou para a memória de Vieira a hora da justiça. ${ }^{1}$

Mas esta apregoada hora da justiça, como podemos deduzir do que é depois dito por Sousa, parecia ocorrer principalmente fora de Portugal. Duas das três biografias por ele referidas não são portuguesas - as escritas por João Francisco Lisboa e pelo padre E. Carel - sendo a única portuguesa citada a de D. Francisco Alexandre Lobo, que fora originalmente publicada em 1823 e depois refundida em $1849^{2}$. Sobre outros escritos, Sousa apenas afirma que passa "em silêncio algumas curtas notícias biográficas mais recentes"3.

Pretendemos aqui preencher, em parte, este silêncio, trabalhando com um tipo específico de recepção da obra de Vieira durante o século

${ }^{1}$ SOUSA, 1887, p.VII.

${ }^{2}$ Cf. SILVA, 1859, tomo II, p. 324. Inocêncio Silva informa que a primeira edição foi publicada em Coimbra, sem o nome do autor, e que a segunda, parte do Tomo II das Obras de D. Francisco Alexandre Lobo, publicada postumamente, é de fato uma nova versão, refundida e modificada, do texto que havia saído em volume 26 anos antes.

${ }^{3}$ SOUSA, 1887, p.VIII. 
XIX: aquela realizada por escritores oitocentistas. Para tanto analisaremos principalmente três imagens de Vieira, presentes em histórias literárias: as contidas no Bosquejo da poesia e língua portuguesa de Almeida Garrett - publicado em 1826 -, no segundo volume do Curso de Literatura Portuguesa - escrito por Camilo Castelo Branco, cuja primeira edição é de 1875 -, e no Os Seiscentistas de Teófilo Braga, publicado pela primeira vez em 1916. Estas três obras permitirão que tracemos um breve esboço da forma vária como a obra de Vieira foi interpretada por escritores portugueses oitocentistas, início de uma pesquisa mais ampla que estamos atualmente desenvolvendo ${ }^{4}$.

Certamente a forma como Almeida Garrett se refere a Vieira no Bosquejo mostra que, na década de vinte do século passado, a apregoada hora da justiça referida por José Fernando de Sousa ainda não havia chegado. Como sabemos, neste livro Garrett traça a evolução da literatura portuguesa desde as suas origens até praticamente a sua época, vendo esta história como um conjunto sucessivo de épocas de esplendor e de decadência: os próprios títulos dos capítulos já trazem implícita esta visão sobre a história da literatura, ${ }^{5}$ que por sinal será,

${ }^{4}$ Como decorrência dessa pesquisa, foi apresentada, no Congresso Internacional $3^{\circ}$ Centenário do Padre António Vieira, a comunicação "Aspectos da recepção de Vieira por escritores portugueses oitocentistas". Cf. OLIVEIRA, 1997.

${ }^{5}$ São os seguintes os títulos das sete partes do Bosquejo:

I - Origem da nossa língua e poesia

II - Primeira época literária; fins do XIII século até aos princípios do XVI século

III - Segunda época literária; idade de ouro da poesia e da língua desde os princípios do XVI até os do XVII século

IV - Terceira época literária; principia a corromper-se o gosto e a declinar a língua. - Começo até o fim do XVII séc.

V - Quarta época: idade de ferro; aniquila-se a literatura, corrompe-se inteiramente a língua. - Fins do XVII, até meados do XVIII séc.

VI - Quinta época: Restauração das letras em Portugal. - Meio do século XVIII até o fim

VII - Sexta época; segunda decadência da língua e literatura; galicismo e traduções.

(GARRETT Apud: SIMÕES, 1964) 
como já mostramos em outro contexto, a forma típica de se pensar não só a literatura, mas a própria história de Portugal durante o século XIX e o início do XX. ${ }^{6}$ Garrett vê, na literatura, um período áureo, "desde os princípios do século XVI até os do XVII", que havia sido preparado pelo período anterior e é seguido por uma decadência que, iniciando-se já no século XVII, atinge seu auge em "fins do XVII até meados do XVIII". ${ }^{8}$ Após isto existe uma recuperação durante a segunda metade do século XVIII, que termina com uma "segunda decadência da língua e literatura", 9 que antecede ao então momento atual.

Como podemos notar, Vieira situa-se para Garrett justamente no período de mais funda decadência, período em que "aniquilase a literatura, corrompe-se inteiramente a língua". ${ }^{10}$ Em vista disto, para podermos entender o significado e o valor que a obra de Vieira possui para o autor do Bosquejo é necessário que, inicialmente, entendamos os motivos pelos quais, para este escritor, entre os fins do século XVII e meados do XVIII existe um período de grande decadência da poesia e da língua.

Para Garrett a inferioridade literária desta época deve-se principalmente ao estilo. No início do terceiro período, que vai do começo até o fim do século XVII, este autor afirma:

Porém os sintomas do Gongorismo e Marinismo se manifestavam já em Itália e Castela; não perfeitos ainda, não no auge a que os levaram os dois poetas, aliás engenhosos, cujo nome vieram a tomar; mas já assim

${ }^{6}$ Como mostramos em nossa tese, a visão de um país que já tendo passado por um período áureo encontra-se em decadência, matricialmente presente no Bosquejo, será recorrentemente utilizada pelos escritores e intelectuais portugueses desde Garrett até, no mínimo, a época da segunda série de $A$ Águia, ou seja, a década de 10 do nosso século. Cf. OLIVEIRA, 1995.

7 GARRETT Apud: SIMÕES, 1964, p.163.

${ }^{8}$ GARRETT Apud: SIMÕES, 1964, p.177.

${ }^{9}$ GARRETT Apud: SIMÕES, 1964, p.188.

${ }^{10}$ GARRETT Apud: SIMÕES, 1964, p.177. 
mesmo a poesia moderna estava toda gafa dessa lepra de soberba requintada. ${ }^{11}$

A independência portuguesa não garantiu, para Garrett, a volta a um estilo mais próprio e nacional. Como ele afirma: "E todavia já nós tínhamos recobrado tão gloriosamente nossa independência, já o nome português tornara a ser honra e nobreza, e ainda essa lepra castelhana lavrava". ${ }^{12}$

É nesse contexto que Garrett tece a sua imagem de Vieira, que é visto como sendo um dos divulgadores dessa lepra, ou seja, em íntima sintonia com as características negativas da época em que viveu:

Dois grandes escritores, ambos prosistas e ambos dignos de muito louvor, concorreram para a continuação deste mal. Quem podia deixar de admirar Vieira? Quem não iria, levado pela torrente de sua eloqüência? Quem resistiria aos ímpetos de arrebatamento de Jacinto Freire? O grande talento de ambos, a vasta erudição e desmedido engenho de Vieira sobretudo, fizeram grande dano à literatura: sabiam, escreviam perfeitamente a língua, tinham grande crédito na corte, tratavam grandes assuntos, animava-os o nobre e sincero entusiasmo da glória e liberdade nacional: tudo foi após eles; imitaram-lhes vícios e virtudes. Como não distinguiam em Vieira o grande orador, o grande filósofo do gongorista afetado (quando o era) (...): ruim e bom seguiram. E como é mais fácil imitar a afectação, que a naturalidade, as argúcias de má arte, que as graças de boa natureza; os imitadores foram além de seus tipos no afectado, no mau deles, ficaram imenso aquém do que nesses era belo e para imitar. ${ }^{13}$

Estamos, como podemos notar, diante de um Vieira multiforme, visto através de sucessivos e complementares ângulos. A imagem mais forte que depreendemos deste texto é o papel que, para Garrett, Vieira tem na história da literatura portuguesa: ele e Jacinto Freire são considerados como os autores que perpetuam a

\footnotetext{
${ }^{11}$ GARRETT Apud: SIMÕES, 1964, p.173.

${ }^{12}$ GARRETT Apud: SIMÕES, 1964, p.178.

${ }^{13}$ GARRETT Apud: SIMÕES, 1964, p.178.
} 
lepra castelhana do gongorismo, sendo, nesta perspectiva, responsáveis diretos pela manutenção e mesmo agravamento da decadência em que, para este autor, então se encontrava a literatura portuguesa. Quando porém, numa segunda camada deste retrato, passamos do papel de Vieira no desenvolvimento da literatura para o valor intrínseco de sua obra, podemos notar que o julgamento de Garrett se torna mais nuançado e menos categórico. Vieira é classificado como grande escritor, possuidor de um grande talento, de uma vasta erudição e de desmedido engenho, um grande orador e grande filósofo, e mesmo um epíteto negativo, o de gongorista afetado, é, como pode ser visto, relativizado por um "quando o era", colocado entre parênteses. Uma terceira camada, que recobre este Vieira, é a do nacionalista, na medida em que é qualificado como alguém que possuía o nobre e sincero entusiasmo da glória e liberdade nacional.

Curiosa imagem esta, em que temos um homem visto de forma positiva pelo amor que dedica à causa da liberdade nacional - e devemos aqui lembrar o papel fundamental que, como notaram Eduardo Lourenço e Helder Macedo, tem o amor à pátria para Garrett ${ }^{14}$-, um escritor que é qualificado, na quase totalidade das vezes, com epítetos positivos, mas que apesar de tudo isto é apontado como um dos responsáveis pelo declínio da literatura nacional. Se esta contradição é atenuada quando Garrett se refere aos imitadores - incapazes de diferenciar o bom do ruim e mais propensos a imitar este último - certamente a imagem de Vieira que é gerada por este trecho acaba por conjugar características inconciliáveis. Parece-nos que Vieira não cabe nos moldes em que Garrett pretende enquadrá-lo, nem na visão que o autor de Viagens na minha terra tem sobre o período em que Vieira viveu, e que por isto surge o descompasso entre uma obra que não consegue menosprezar, e o uso de um estilo que para ele é a antítese de tudo o que é positivo. Assim, ficamos diante de um Vieira duplo, positivo

${ }^{14}$ Cf. LOURENÇO, 1982, p.94; MACEDO, 1979, p. 15-24. 
em alguns aspectos, negativo em outros, sem que exista uma ponte através da qual estes dois lados sejam articulados.

Será quase cinqüenta anos depois deste texto de Garrett que Camilo Castelo Branco publicará o segundo tomo do Curso de Literatura Portuguesa. Como sabemos, este curso havia sido planejado por José Maria de Andrade Ferreira, que morreu após ter escrito o primeiro volume, que compreendia a história da literatura portuguesa até 1580. Camilo Castelo Branco, aceitando o pedido dos editores, ${ }^{15}$ escreveu o segundo volume, em que analisa a literatura portuguesa de 1580 até as obras de Almeida Garrett e Feliciano de Castilho.

O discurso de Camilo sobre Vieira, se possui várias especificidades em relação ao de Garrett, também apresenta, como veremos, algumas semelhanças em relação a este último. Mas, para que possamos entender todo o seu significado, é importante que notemos que o autor de Anátema utiliza, em seu texto, um grande excerto de Castilho, retirado da obra Padre Manuel Bernardes, cuja primeira edição é, provavelmente, de $1845 .{ }^{16}$ Este longo trecho, que ocupa mais de uma página no livro de Camilo, é todo composto por um contraponto entre os sermões do Padre Manuel Bernardes e os de António Vieira. Nesta comparação, Vieira é recorrentemente apresentado como um autor artificial, mais preocupado com a eloqüência do que com a verdade, disposto a tudo sacrificar em nome de sua originalidade. Um breve trecho poderá indicar o tom depreciativo com que a obra de Vieira é analisada por Castilho:

${ }^{15}$ Cf. FERREIRA, CASTELO BRANCO, 1875, Tomo II. "Explicação" (sem paginação).

${ }^{16}$ Não tivemos acesso a este livro de Castilho. No Curso de Literatura Portuguesa, em nota, é dada a seguinte indicação: "A. F. Castilho - Livraria Clássica, Pe. Manuel Bernardes, ediç. 1865, pág. 284 e seg.”. (Idem, p.107). Julgamos que a primeira edição deste livro é de 1845, devido às informações presentes em PIRES, Lucília Gonçalves. Imagens da obra do padre Manuel Bernardes. Lisboa: Seara Nova, 1978. p.23. 
Vieira sacrificava tudo à sua necessidade suprema, ao empenho de ser original e único; sacrificava-lhe a verdade; sacrificava-lhe a verosimilhança; sacrificava até a possibilidade; não hesitava em propor o princípio mais absurdo, como fosse ou parecesse novo; e, como para lá não achava caminho pela lógica, fabricava-o com pontes sobre pontes, através dum oceano de sofismas, de argúcias, de puerilidades, de indecências, de quase heresias (....). Vieira zomba freqüente vezes de nossa credulidade; podemos desconfiar da convicção de Vieira, ainda quando nos fala certo. ${ }^{17}$

É conhecida a admiração que Camilo tinha por Castilho. ${ }^{18}$ Assim, não é de estranhar que este trecho do autor de Os Ciúmes do Bardo tenha influenciado a visão que, em seu livro, Camilo expressa sobre Vieira. É, por sinal, com um trecho do Padre Manuel Bernardes que Camilo inicia a sua análise da obra de Vieira, trecho no qual o autor de Luz e Calor critica os sermões em que "o estilo com que se tratam [as matérias do sermão] é tão aceitado, tão sumido em descrições, tão estofado de lumes retóricos, tão pendurado de correspondências de palavras e períodos, que não pode o sério e espiritual do assunto lograr a sua eficácia". ${ }^{19}$

Este trecho de Bernardes, todo montado em tom depreciativo sobre os que ornam os assuntos sacros com inúteis ouropéis, é seguido do seguinte comentário de Camilo: "Em parte ou no todo destas argüições indiretas avultariam talvez ao sensato ânimo do padre Manuel Bernardes os estrondosos sermões do aclamado príncipe da eloqüência do púlpito português [padre António Vieira]". ${ }^{20}$

O trecho de Bernardes e o comentário posterior de Camilo poderiam indicar que também ele, como Castilho, expressaria uma

${ }^{17}$ CASTILHO Apud FERREIRA, CASTELO BRANCO, 1865, p.107.

${ }^{18}$ A este respeito ver o verbete sobre Castilho presente em CABRAL, 1988, p.159-161.

${ }^{19}$ BERNARDES, Apud. FERREIRA, CASTELO BRANCO, 1865, p.101.

${ }^{20}$ FERREIRA, CASTELO BRANCO, 1865, p.102. 
visão bastante depreciativa da obra de Vieira. Isto em parte ocorre, e o autor de Amor de Perdição é impiedoso com o estilo do jesuíta, considerando que ele enredava sua frases em um "sarilho vicioso", que "deleitava-se em pintar a caricatura da eloqüência sagrada" ou que "rematava umas conclusões tão alheias dos princípios, que o auditório pasmava da solércia do orador, como das peripécias imprevistas de uma comédia de Alarcão". ${ }^{21}$ Camilo não se esquecerá mesmo de, seguindo as trilhas de Garrett, apontar o efeito pernicioso que a eloqüência de Vieira teve em seus imitadores, e considerará que estes "desceram à ínfima relaxação a oratória sacra”, afirmando, para comprovar o seu dito, que os "sermonários do século XVII (...) provam que não há grau determinado para a baixeza da arte corrompida". ${ }^{22}$

Mas, ao lado desta visão depreciativa, Camilo também expressará uma outra perspectiva sobre Vieira. Para entendermos o significado desta segunda faceta, é importante que lembremos aqui da importância que o autor de $A$ Queda dum Anjo atribuía à escrita em vernáculo, ao uso de um português correto e castiço. Um bom indicador desta postura pode ser percebido na própria forma como Castilho é valorizado no Curso de Literatura Portuguesa, o que é feito considerando-o como o mais luminoso e vernáculo prosador português e como quem atingiu a suprema perfeição da lingua portuguesa. ${ }^{23}$ Será justamente através da língua que Camilo irá construir uma outra face de Vieira, como podemos ver no trecho abaixo:

São os sermões do padre António Vieira uns riquíssimos minérios do mais fino ouro pelo que respeita à linguagem. Ninguém reuniu em poucas páginas tantas palavras rubricadas pelos mestres que o precederam. As opulências que Vieira aditou à prosódia constituiriam

\footnotetext{
${ }^{21}$ FERREIRA, CASTELO BRANCO, 1865, p.104-105.

${ }^{22}$ FERREIRA, CASTELO BRANCO, 1865, p.105.

${ }^{23}$ FERREIRA, CASTELO BRANCO, 1865, p.106, p.275.
} 
o idioma português no alto ponto das línguas mais ricas, se já então houvéssemos entrado em comunhão de ciências com a Europa (...). O seu modo de adjetivar é irrepreensível; a propriedade do epíteto é nele tão original que a não podemos derivar de Camões nem de Barros. ${ }^{24}$

Como podemos notar, estamos aqui diante de um outro Vieira, construído através de características positivas, em oposição a todo o lado negativo que Camilo também lhe atribui. Esta distância entre um Vieira cultor e aperfeiçoador da lingua portuguesa e o Vieira detentor de uma eloqüência viciosa fica bastante clara em dois outros trechos da análise que Camilo faz sobre os Sermões.

No primeiro destes, ele afirma: "Quem se votasse à agradável tarefa de colher palavras e frases nos sermões de Vieira, desenredando-as do sarilho vicioso em que ele as envencilhava, formaria um florilégio, um bastantíssimo vocabulário e seleta prosódia para exercícios de primorosa escrita". ${ }^{25}$

No segundo trecho, em que a dupla face de Vieira fica ainda mais evidente, é dito: "O estudioso de vernaculidade assombra-se, e estuda-o [a Vieira] com delícias; o pregador que hoje quisesse imitá-lo seria irrisório". ${ }^{26}$

Como havíamos afirmado ao iniciar a análise do Curso de Literatura Portuguesa, a imagem de Vieira construída por Camilo, apesar de ser montada a partir de perspectivas bastante distintas das do autor de Folhas Caídas, acaba por ter pontos de contato com ela. Se Garrett e Camilo se afastam no valor intrínseco que atribuem à obra de Vieira - na sua maior parte, como notamos, positiva para o primeiro e negativa para o segundo desses escritores -, aproximam-se não só ao considerarem que o autor dos Sermões inicia ou mantém uma tradição maléfica, mas também no fato de acabarem por construir a imagem de um Vieira cindido, visto por

\footnotetext{
${ }^{24}$ FERREIRA, CASTELO BRANCO, 1865, p.104.

${ }^{25}$ FERREIRA, CASTELO BRANCO, 1865, p.104. Os grifos são nossos.

${ }^{26}$ FERREIRA, CASTELO BRANCO, 1865, p.105.
} 
duas perspectivas distintas e, em certo sentido, inconciliáveis. Se Garrett havia atribuído ao jesuíta o amor à pátria, uma característica para ele fundamental, Camilo verá Vieira como um vernáculo prosador em que é atingida, em vários aspectos, a perfeição da lingua portuguesa, características estas de grande valor para o autor de Anátema. Ou seja, em ambos os casos, Vieira acaba sendo construído como um ser duplo, em que determinadas características negativas - sempre vistas como preponderantes - acabam por conviver com aspectos positivos, de inegável valor para cada um dos dois escritores.

Bem outra será a imagem de Vieira elaborada por Teófilo Braga quando, em 1916 - ou seja cerca de quarenta anos após o Curso de Literatura Portuguesa-, publica Os Seiscentistas. ${ }^{27}$ De início devemos notar que, diferentemente de Camilo e Garrett, a maior parte do estudo de Teófilo recairá sobre a vida, e não sobre a obra de Vieira. De fato, toda a parte dedicada especificamente a este escritor é, como indica Teófilo, um resumo da "obra magistral de João Francisco Lisboa, Vida do Pe. Vieira", ${ }^{28}$ e nesta parte, apenas o homem, e não as obras que produziu, está em questão. Como o nosso principal interesse, neste momento, é o de analisar a recepção crítica da obra de Vieira, não nos deteremos muito sobre esta parte. Gostaríamos apenas de assinalar que a imagem que nela é construída é a de um homem apenas fiel à Companhia de Jesus, para quem "toda a pátria é uma terra estrangeira, e toda a terra estrangeira uma pátria". ${ }^{29}$ Vieira, que fora um nacionalista para Garrett, se transforma, sob a pena de Teófilo Braga, em alguém que "despen-

${ }^{27}$ Algumas das reflexões de Teófilo Braga sobre Vieira, presentes neste livro, já haviam sida publicadas em BRAGA, 1875, p.398-401 e em BRAGA, 1885, p.315-319. Nestes dois livros, porém, a imagem construída de Vieira não é tão negativa como a presente em Os Seiscentistas.

${ }^{28}$ BRAGA, s.d, p.377.

${ }^{29}$ BRAGA, s.d, p.378. 
deu a sua actividade nas estéreis intrigas políticas em que muito prejudicou a combalida autonomia da nação portuguesa" ${ }^{30}$

Será apenas em um segmento mais geral de sua obra, sobre a eloqüência sacra, que Teófilo Braga analisará, mesmo que de forma parcial, a obra de Vieira. É nesta parte que poderemos perceber que o autor de Os Seiscentistas acaba por se filiar a um tipo de análise que já havíamos encontrado em Camilo, que, como notamos, já a havia haurido de Castilho: a que se utiliza do padre Manuel Bernardes e de seus textos como instrumento para avaliar a obra de Vieira. Os mesmos trechos de Os últimos fins dos homens (...) citados por Camilo, junto a alguns outros também presentes neste livro de Bernardes, serão utilizados por Braga para criticar os sermões de Vieira, com resultados bastante próximos àqueles que já encontramos no Curso de Literatura Portuguesa. Também aqui a opinião de Manuel Bernardes, sobre a necessidade de se evitar o uso de uma linguagem muito artificiosa, é assumida como correta e utilizada para mostrar o quão imperfeita era a arte de Vieira.

Mas este mecanismo não será o único a ser utilizado para depreciar a obra do autor dos Sermões. Ao lado dele encontramos um outro: o de usar Vieira contra si mesmo. Esta estratégia, que pode ser notada explicitamente em um momento, e que surge de forma mais velada em outros, parece-nos ser a marca mais original desta crítica de Teófilo, por mais que também aqui possamos encontrar ecos da visão de Camilo Castelo Branco. Se este último autor havia dito que os sermões de Vieira lembravam muitas vezes as peripécias imprevistas de uma comédia de Alarcão, Teófilo desenvolverá este mote, citando um longo fragmento do sermão da Sexagésima em que "estabelece-se uma relação entre os Sermões e as Comédias"31, do qual retiramos o trecho abaixo:

(...)antigamente pregavam bradando, hoje pregam conversando... os ouvintes vêm como à comédia, e há pregadores que vêm ao púlpito

\footnotetext{
${ }^{30}$ BRAGA, s.d, p. 382.

${ }^{31}$ BRAGA, s.d, 375.
} 
como à comédia; há pregação e pregadores que vêm ao púlpito como comediantes. Uma das felicidades que se contava entre as do tempo presente, era acabarem-se as Comédias em Portugal; mas não foi assim; não se acabaram, mudaram-se do teatro para o púlpito. ${ }^{32}$

Após citar este trecho, Teófilo Braga comentará: "O próprio Vieira era arrastado nesta corrente do gosto público, e a aristocracia mandava deitar de manhã tapetes na igreja de S. Roque, para ir ouvilo à tarde". ${ }^{33}$ Este procedimento, de usar argumentos de Vieira contra ele próprio, será utilizado de forma mais velada mais duas vezes, em que são citados outros trechos de sermões.

Como podemos notar, nesta análise de Teófilo o aspecto duplo que caracterizou a apreciação crítica de Vieira feita por Camilo e por Garrett acaba por aparecer de forma totalmente transmutada. Não se trata mais de ver características positivas e negativas na obra do autor dos Sermões, mas em mostrá-lo como um ser duplo e dúbio, que critica posturas que, na visão de Teófilo Braga, o próprio Vieira acaba por assumir em sua obra. Este caráter dúbio é, por sinal, o mais importante traço com que Teófilo pinta o seu retrato de Vieira, traço que acaba por irmanar a obra e o homem: seja enquanto jesuíta, seja como homem político, seja como escritor, o autor dos Sermões é recorrentemente visto como alguém "sempre fértil de expedientes e com lábia". ${ }^{34}$

Este breve esboço que aqui fizemos da apreciação crítica sobre a obra de Vieira por alguns escritores oitocentistas nos mostra o quão equivocado estava José Fernando de Sousa ao afirmar que soara para a memória de Vieira a bora da justiça. Pelo que pudemos perceber, os juízos sobre Vieira tenderam todos a ter, como principal característica, o tom negativo e, pensando apenas nas três obras sobre as quais detivemos mais a nossa atenção - as de Almeida

\footnotetext{
${ }^{32}$ VIEIRA, Apud BRAGA, s.d., p. 375. Os grifos são de Teófilo Braga.

${ }^{33}$ BRAGA, s.d., p. 375.

${ }^{34}$ BRAGA, s.d., p. 379.
} 
Garrett, Camilo Castelo Branco e Teófilo Braga -, existe mesmo uma visão cada vez mais depreciativa sobre obra desse autor.

Esta breve visada sobre a apreciação crítica dos Sermões só vem a mostrar a necessidade de uma pesquisa de maior fôlego e sobre um período mais abrangente, para que possamos entender como António Vieira, tão incompreendido no século passado e ainda no início deste, acabou por ocupar o papel de destaque que hoje possui na história da literatura portuguesa, papel que os inúmeros eventos que ocorreram em 1997, comemorando o terceiro centenário de sua morte, só vêm a confirmar.

\section{Referências Bibliográficas}

BRAGA, Teófilo. Curso de História da Literatura Portuguesa. Lisboa: Nova Livraria Internacional, 1885.

BRAGA, Teófilo. História da Literatura Portuguesa III - Os Seiscentistas. Lisboa: Europa-América, s.d.

BRAGA, Teófilo. Manual da História da Literatura Portuguesa desde as suas origens até o presente. Porto: Livraria Universal de Magalhães \& Moniz, 1875.

CABRAL, Alexandre. Dicionário de Camilo Castelo Branco. Lisboa: Caminho, 1988.

FERREIRA, José Maria de Andrade, CASTELO BRANCO, Camilo. Curso de Literatura Portuguesa. Lisboa: Livraria Editora de Mattos Moreira \& Cia, 1875.

GARRETT, Almeida. Bosquejo da História da Poesia e Língua Portuguesa. Apud: SIMÕES, João Gaspar. Almeida Garrett. Lisboa: Presença, 1964. p. 156-200.

GARRETT, Almeida. Bosquejo da História da Poesia e Língua Portuguesa. Lisboa: Empresa da História de Portugal, 1904.

LOURENÇO, Eduardo. O Labirinto da Saudade. Lisboa: Dom Quixote, 1982. 
MACEDO, Helder. As viagens na minha terra e a menina dos rouxinóis. Colóquio Letras, 51, set. 1979. p. 15-24.

OLIVEIRA, Paulo Motta. Aspectos da recepção de Vieira por escritores portugueses oitocentistas. Resumos das Comunicações - $3^{\circ}$ Centenário do P. António Vieira - Congresso Internacional. Lisboa: Universidade Católica Portuguesa e Companhia de Jesus, 1997. p. 150.

OLIVEIRA, Paulo Motta. Esperança e Decadência: as imagens de Portugal na segunda série de A Águia. Campinas: Instituto de Estudos da Linguagem da UNICAMP, 1995. (Tese, Doutorado em Teoria da Literatura).

PIRES, Lucília Gonçalves. Imagens da obra do padre Manuel Bernardes. Lisboa: Seara Nova, 1978.

SILVA, Inocêncio Francisco. Dicionário Bibliográfico Português. Lisboa: Imprensa Nacional, 1859.

SOUSA, José Fernando de. Notícia Biográfica. Trechos Selectos do Padre António Vieira - Publicação comemorativa do bicentenário da sua morte. Lisboa: Tipografia Minerva Central, 1887.

\section{Resumo}

Este trabalho visa a refletir sobre a forma como a obra de Vieira foi analisada por Almeida Garrett, Camilo Castelo Branco e Teófilo Braga.

\section{Abstract}

This paper intends to analyse how Vieira's works was interpreted by Almeida Garrett, Camilo Castelo Branco and Teófilo Braga. 